\title{
Tecnologias Educacionais no ensino híbrido de Enfermagem
}

\author{
Educational Technologies in hybrid Nursing education \\ Tecnologías Educativas en la educación híbrida de Enfermería
}

Recebido: 13/07/2021 | Revisado: 19/07/2021 | Aceito: 21/07/2021 | Publicado: 28/07/2021

\author{
Alessandra Conceição Leite Funchal Camacho \\ ORCID: https://orcid.org/0000-0001-6600-6630 \\ Universidade Federal Fluminense, Brasil \\ E-mail: alessandracamacho@id.uff.br \\ Vitória Meireles Felipe de Souza \\ ORCID: https://orcid.org/0000-0002-1129-6324 \\ Universidade Federal Fluminense, Brasil \\ E-mail: vifelipe@id.uff.br
}

\begin{abstract}
Resumo
Este artigo tem como objetivo descrever algumas tecnologias educacionais no ensino híbrido de Enfermagem com vistas ao desenvolvimento da autonomia discente. É uma proposta de relato de experiência, com abordagem qualitativa do tipo descritiva sobre as tecnologias educacionais no ensino híbrido na Enfermagem. Este artigo está pautado nas seguintes discussões: o planejamento da disciplina e o ensino híbrido; o ambiente virtual e as tecnologias educacionais que permeiam o ensino de Enfermagem com o respeito do ritmo de aprendizagem de cada aluno onde requer uma nova postura do professor. Este como mediador deve inovar, conhecer as ferramentas digitais, saber efetivar as práticas pedagógicas e conhecer a realidade social de seus estudantes. Como conclusão entende-se que pensar no ensino híbrido na área da Enfermagem é enfatizar o protagonismo do aluno com autonomia de forma participativa e reflexiva requerendo um ensino interdisciplinar por competências capaz de compreender as demandas do mundo atual, considerando uma formação integral do sujeito aprendiz. Disposição para inovar, conhecer as ferramentas digitais, saber efetivar as práticas pedagógicas e conhecer a realidade social de seus estudantes.
\end{abstract}

Palavras-chave: Ensino híbrido; Tecnologia educacional; Ensino superior; Enfermagem.

\begin{abstract}
This article aims to describe some educational technologies in the hybrid teaching of Nursing with a view to developing student autonomy. It is a proposal for an experience report, with a qualitative descriptive approach on educational technologies in hybrid teaching in Nursing. This article is based on the following discussions: discipline planning and hybrid teaching; the virtual environment and the educational technologies that permeate Nursing education with respect for each student's learning pace, which requires a new attitude from the teacher. As a mediator, he must innovate, know the digital tools, know how to implement pedagogical practices and know the social reality of his students. In conclusion, it is understood that thinking about hybrid teaching in the field of Nursing is to emphasize the protagonism of the student with autonomy in a participatory and reflective way, requiring interdisciplinary teaching based on competences capable of understanding the demands of the current world, considering an integral formation of the learner subject. Willingness to innovate, know the digital tools, know how to implement pedagogical practices and know the social reality of its students.
\end{abstract}

Keywords: Hybrid teaching; Educational technology; University education; Nursing.

\section{Resumen}

Este artículo tiene como objetivo describir algunas tecnologías educativas en la enseñanza híbrida de Enfermería con miras al desarrollo de la autonomía del estudiante. Se trata de una propuesta de relato de experiencia, con enfoque descriptivo cualitativo sobre tecnologías educativas en la enseñanza híbrida en Enfermería. Este artículo se basa en las siguientes discusiones: planificación disciplinaria y enseñanza híbrida; el entorno virtual y las tecnologías educativas que impregnan la formación de Enfermería con respeto al ritmo de aprendizaje de cada alumno, lo que exige una nueva actitud por parte del docente. Como mediador, debe innovar, conocer las herramientas digitales, saber implementar prácticas pedagógicas y conocer la realidad social de sus alumnos. En conclusión, se entiende que pensar en la enseñanza híbrida en el campo de la Enfermería es enfatizar el protagonismo del estudiante con autonomía de manera participativa y reflexiva, requiriendo una enseñanza interdisciplinaria basada en competencias capaces de comprender las demandas del mundo actual, considerando una formación integral del sujeto aprendiz. Voluntad de innovar, aprender sobre herramientas digitales, saber implementar prácticas pedagógicas y conocer la realidad social de sus estudiantes.

Palabras clave: Enseñanza híbrida; Tecnologia Educacional; Educación superior; Enfermería. 


\section{Introdução}

Nos dias atuais com o advento da Pandemia da COVID-19 as tecnologias educacionais foram consideradas ferramentas importantes que auxiliam no ensino acadêmico com vista a ampliação de novas conexões de comunicação e aprendizado. Novas formas de aprender e ensinar impulsionaram os docentes a reflexões sobre a maneira de potencializar o ensino, sendo facilitador na condução de conteúdos que são discutidos na disciplina com objetivo de incentivar a autonomia do discente (Santos Junior, \& Monteiro, 2020).

Diante desta realidade, o Ensino Híbrido (Blended Learning) é a utilização de metodologia do ensino presencial, unificado ao ensino online, no desenvolvimento do processo de ensino e aprendizagem com o auxílio de plataformas virtuais. São aulas e conteúdos participativos e flexíveis, colocando o aluno como protagonista do seu aprendizado motivando-o a participar da construção do seu conhecimento de forma ativa em grupo ou individualmente (Júnior, \& Castilho, 2016).

O ensino híbrido é uma proposta de integração das tecnologias educacionais ao ensino, cujo aluno aprende de forma presencial e online possibilitando o ritmo de aprendizado de acordo com as especificidades de cada indivíduo (Rodrigues, 2016). Esse método permite que o professor mediador do conhecimento apresente acesso de forma individualizada a maneira como cada aluno apreende e troca conhecimentos através de atividades individuais e em grupo de acordo com os conteúdos trabalhados presencialmente e virtual (Moran, 2017).

Repensar o papel docente no ensino híbrido face com as tecnologias educacionais pode ser gratificante gerando novas ideias para a prática pedagógica no âmbito educacional. Nesta nova perspectiva, a responsabilidade de ensinar e aprender se abre para novas relações entre conteúdos, espaços, tempos e pessoas (Andrade, \& Monteiro, 2019).

Nesse tipo de ensino é possível utilizar diversos recursos que possibilitem alcançar os objetivos e as estratégias de aprendizagem planejadas na disciplina. Além disso, possibilita o desenvolvimento do ensino de forma contínua e personalizada de acordo com o perfil discente. Nesta perspectiva é a possibilidade de mudança do paradigma que privilegia a transmissão de informações para o paradigma focado no desenvolvimento de competências, em que o protagonismo do aluno é essencial (Santos, \& Hansel, 2021).

Não é uma tarefa fácil e exige do professor que é mediador do conhecimento um planejamento atualizado e dinâmico bem como, capacitação docente e investimento contínuo pelas universidades, institutos e unidades de ensino acadêmico. Realidade está ainda difícil em nosso país (Castro et al., 2015). O ensino híbrido abre o horizonte de aprendizado tendo a tecnologia como aliada. Portanto, como a tecnologia poderá propiciar ferramentas educacionais no contexto da Enfermagem e suas áreas correlatas, possibilidades para que alunos e professores interajam e discutam as habilidades e competências necessárias que proporcionem reflexões para o ensino acadêmico com vista a contribuições relevantes (Gomes, 2019).

Assim, o objetivo deste artigo é descrever algumas tecnologias educacionais no ensino híbrido de Enfermagem com vista ao desenvolvimento da autonomia do discente.

\section{Metodologia}

É uma proposta de relato de experiência, com abordagem qualitativa do tipo descritiva sobre as tecnologias educacionais no ensino híbrido na Enfermagem. Possui uma diretriz de interação dialógica que orienta o desenvolvimento de relações entre Universidade marcados pelo diálogo e troca de saberes.

A importância do desenvolvimento deste artigo originou-se no planejamento das disciplinas da graduação em Enfermagem que em virtude da Pandemia da Covid-19 passou do ensino presencial para o ensino remoto. No entanto, atualmente com vistas a melhores oportunidades de aprendizagem vislumbra-se o ensino híbrido.

Este trabalho se insere como um oportuno produto do curso de graduação em Enfermagem e da pós-graduação da Escola de Enfermagem Aurora de Afonso Costa, da Universidade Federal Fluminense, mais precisamente em experiências como 
docente nas disciplinas de Fundamentos de Enfermagem e Cuidados Clínicos pertencente ao Programa Acadêmico em Ciências do Cuidado em Saúde da mesma instituição.

Esse artigo se caracteriza por apresentar abordagem do tipo acadêmica e qualitativa, realizada por meio da coleta de dados obtidos diretamente no contexto de determinado acontecimento, a partir da utilização do uso de métodos de estudos de fenômeno social. Além disso, trata-se de um estudo de caso uma vez que possui análise e descrição de maneira detalhada de algum caso que apresente particularidade, o tornando especial (Pereira, Shitsuka, Parreira, \& Shitsuka, 2018).

Este artigo está pautado nas seguintes discussões: O planejamento da disciplina e o ensino híbrido; O ambiente virtual e as Tecnologias Educacionais que permeiam o ensino de Enfermagem.

\section{Resultados e Discussão}

\section{O planejamento da disciplina e o ensino híbrido}

Tendo o planejamento da disciplina com enfoque no ensino híbrido é necessário entender as suas características que nos ajudam a direcionar as estratégias de ensino. Portanto, como características temos: o respeito do ritmo de aprendizagem de cada aluno onde requer uma nova postura do professor; possibilidade do planejamento do ensino por estações de aprendizagem em grupos; o incentivo do protagonismo do aluno com autonomia de forma participativa e reflexiva (Santos, Pereira, Barreto, Souza, \& Cicarelli, 2019).

A metodologia híbrida, com a oferta de ferramentas da tecnologia digital, apesar de ser atraente aos alunos e proporcionar sua autonomia, permitindo aulas mais dinâmicas, não pode ser entendida como substituta das aulas presenciais, deve ser considerada como uma convergência do ensino virtual com o presencial, ou seja, contato com o professor e demais alunos continua sendo considerado fundamental para o aprendizado (Andrade, \& Monteiro, 2019).

Para materialização dessa autonomia discente é preciso trazer o aluno para a troca de conhecimentos e não como mero receptor. Desta forma, tendo o aluno como o centro do processo é permitido mudar a cultura avaliativa para uma autoavaliação discente. Ou seja, é uma ferramenta estratégica de melhoria para o aprendizado discente e não como uma forma punitiva. E inicia com a postura de acolhimento do aluno e dá centralidade da aprendizagem pelo aluno aprofundando o conhecimento construído. É preciso pensar em estratégias motivadoras com objetivos de aprendizagem bem estabelecidos e participativos propiciando a colaboração entre os pares no processo de ensino aprendizagem.

O ensino passa por profundo processo de mudança e enfrenta desafios no sentido de buscar meios e alternativas para ressignificar sua prática e repensar o modelo educativo vigente. Essa mudança tem sido impulsionada principalmente pelos alunos da contemporaneidade que não aceitam mais um modelo de educação que os mantenham passivos. Isso ocorre devido à facilidade de acesso à informação que esse aluno tem mediado pelas Tecnologias Digitais de Informação e Comunicação (Andrade, \& Monteiro, 2019; Weber, \& Olgin, 2020)).

Com essas características cabe algumas reflexões no sentido de pensar a aula para além da transmissão de conteúdo com uma escuta do aluno, do professor e, também da instituição de ensino. Para tanto, é importante destacar a função nos atores envolvidos no processo quanto a organização curricular em que o ensino híbrido requer uma interdisciplinaridade e um ensino por competências capaz de compreender as demandas do mundo atual, considerando uma formação integral do sujeito aprendiz.

O construtor de conhecimento utiliza a tecnologia para buscar informações avaliando a precisão, credibilidade e relevância dos dados, explorando questões e problemas do mundo real. O pensador computacional desenvolve estratégias utilizando recursos de tecnologia para resolver problemas (Santos, \& Hansel, 2021; Schlemmer, 2018).

Leva-se em consideração os benefícios e o modo consciente de riscos, sendo importante a manutenção da criticidade para que ocorram avanços tecnológicos e que sejam reconhecidos os benefícios e riscos advindos, levando o aluno ao 
desenvolvimento e ao amadurecimento de inserção de novas propostas a serem incorporadas em seu processo de aprendizagem permeado pelas tecnologias (Silva et al, 2021; Rolindo, et al, 2019).

Outro aspecto é a infraestrutura física que deve gerenciar as demandas e necessidades de espaços acadêmico que compreendam as mudanças pedagógicas a partir do ensino híbrido como laboratórios de habilidades e de simulação realística que auxiliam no ensino por grupos. Além de mobiliário flexível, espaço de convivência, estudo e pesquisa, disponibilidade de equipamentos tecnológicos e digitais. Neste aspecto do processo de ensino aprendizagem, o professor precisa estabelecer características do ensino híbrido no seu planejamento, metodologia, avaliação e os estudantes necessitam entender o seu protagonismo no processo de sua aprendizagem. O professor como mediador do conhecimento no Ensino Híbrido deve possuir disposição para inovar, conhecer as ferramentas digitais, saber efetivar as práticas pedagógicas e conhecer a realidade social de seus estudantes.

Portanto o papel do professor na educação contemporânea deve ser de desconstruidor de um método tradicional para facilitador do conhecimento no processo ensino e aprendizagem. A atualidade sugere papéis híbridos, tanto do professor quanto do aluno, pois o mais importante é a construção do conhecimento sem tornar tão relevante a posição que os atores da educação ocupam neste processo (Andrade, \& Monteiro, 2019).

Com esse entendimento dos atores educacionais dentre os quais os docentes e as instituições devem realizar um planejamento condizente com a ementa da disciplina e do Projeto Político Pedagógico curso Enfermagem. Cabe destacar que o planejamento do Design Didático da disciplina no formato online deve possuir visibilidade e deve trazer um espelho do que será delineado no formato presencial, uma vez que o ensino híbrido contempla o ensino online de forma dinâmica e personalizada.

Os objetivos de aprendizagem devem coadunar com os conteúdos ministrados também devem ser estabelecidos de forma a contextualizar o processo de avaliação de acordo com a estrutura da disciplina com a utilização de Tecnologias Educacionais no ambiente virtual de aprendizagem que previamente é estabelecido para o prosseguimento do ensino híbrido.

\section{O Ambiente virtual de aprendizagem}

O Ambiente virtual de aprendizagem (AVA) adotado pela universidade na área da saúde e, no caso da Enfermagem, permite a utilização de diversas mídias e conteúdos integrados favorecendo a discussão de assuntos pertinentes às disciplinas e dinamizar o ambiente de aprendizagem.

As novas tecnologias oferecem perspectivas possíveis para que as pessoas tenham flexibilidade de tempo e espaço para a apropriação do conhecimento por meio do ciberespaço. Os AVAs, nesse sentido, se constituem em importantes espaços que propiciam a mediação e interação do estudante na aprendizagem servindo como suporte para o ensino mediado pela tecnologia (Pereira, Alvarenga, Teixeira, \& Mansur, 2018).

O objetivo é transformar o conteúdo em algo mais leve, de fácil acesso e consumo, para que os alunos consigam discutir o conteúdo ministrado e as Tecnologias Educacionais no ensino híbrido servem como mediador para a construção do conhecimento, porque conecta professores, alunos e o próprio conteúdo.

Nesse sentido, o AVA precisa apresentar discussões teóricas e metodologia pedagógica de ensino híbrido utilizando o ambiente virtual AVA, cujas atividades planejadas devem surgir a partir de uma problematização, a partir dos diálogos dos estudantes com reflexões na plataforma de ensino esperando-se, como resultado, estimular a inclusão das tecnologias de informação e comunicação como ferramenta de auxílio de ensino e aprendizagem em prol da aprendizagem pelos estudantes com possibilidades na formação de estudantes reflexivos e críticos (Pereira, Alvarenga, Teixeira, \& Mansur, 2018).

No ensino híbrido, o estudante deve estudar on-line, usando o AVA sendo complementado o estudo na instituição de ensino, de maneira a utilizar as metodologias e instrumentos do ensino presencial. É preciso que o estudante tenha o controle e organização em relação ao tempo, que condizem com o seu ritmo de aprendizagem. Tal fato justifica usar AVA e fornecer 
possibilidades de individualização e personalização do aprendizado. Naturalmente, é real ao estudante a necessidade flexibilizar o ritmo e tempo relacionado ao estudo, assim, é essencial atividades que abrangem os diversos estilos de aprendizagem, de maneira a incentivar competências e habilidades (Machado, Lupepso, \& Jungbluth, 2016).

Para além, é conferido alguns princípios da Educação Híbrida onde deve ocorrer: incentivo ao desenvolvimento da autonomia dos estudantes, possibilitando a flexibilização do tempo e a determinação do momento oportuno para solucionar as atividades propostas; ocorre com a junção das tecnologias digitais ao ensino gerando novas possibilidades de aprendizado; uso de uma plataforma virtual cujos docentes e discentes estudantes interagem em determinado ambiente comum, a partir disso se torna possível incorporar as atividades, fóruns de discussões, materiais didáticos, entre outras propostas; bem como, aquisição individualizada acerca do desempenho dos estudantes ajudando no desenvolvimento de diversas estratégias de ensino conforme as necessidades de cada indivíduo (Machado, Lupepso, \& Jungbluth, 2016).

Desta forma, o AVA possibilita mesclar a sala de aula tradicional com recursos digitais, pelos quais o aluno pode estudar em uma sala de aula virtual, em seu próprio ritmo. Além disso, oferece um rápido feedback, processo considerado o motor de reorientação, ou seja, todos os componentes usados para verificar a aprendizagem precisam reagir aos resultados obtidos pelos alunos em uma determinada atividade (Silva, \& Dos Santos Junior, 2019).

No AVA o aluno começa a criar uma identidade de estudante online dentro do sistema para que seja permitido a comunicação entre professores e alunos, postagens em fóruns criados pelo professor, envio de atividades por diversos documentos (texto, planilha, apresentação e desenho), envio de links, imagens e/ou vídeos. A interface AVA precisa permitir uma navegação intuitiva, fazendo com que seu uso se torne natural para o aluno já habituado com o design didático que deve ser orientado pelo professor que é o grande mediador do conhecimento. Nesse sentido, o modelo do AVA busca tornar o ensino mais atraente e problematizador por meio da entrada do estudante no espaço digital em que o ensino não apresente o viés de centralização na figura do professor mas que seja percebido o professor provocador, em que o conhecimento é construído pelo próprio aluno ao tentar solucionar as situações problema (Pereira, Alvarenga, Teixeira, \& Mansur, 2018).

\section{As Tecnologias Educacionais}

As habilidades no uso dos ambientes virtuais de aprendizagem na formação acadêmica tornam-se viáveis através de ferramentas a ser aperfeiçoada a prática pedagógica pelos docentes a fim de realizar transformações que ressignifiquem saberes e práticas e concepções advindas com o uso de tecnologias digitais (Silva et al., 2021).

As tecnologias digitais possuem um papel importantíssimo no contexto da educação. No entanto, os professores ainda não detêm o conhecimento preciso para a utilização de ferramentas e tecnologias da atualidade em seu ensino, apesar desse mecanismo facilitar o acesso rápido a uma grande quantidade de informações, proporcionando ao aluno compartilhar conteúdo (Bacich Neto, \& Trevisani, 2015).

Exige uma mudança educacional que depende da qualidade de formação dos professores para determina suas práticas pedagógicas. Outrossim, não se podem introduzir as tecnologias sem antes pensar nos objetivos e benefícios do seu uso. Com isso, é preciso pesquisas, planejamento e desenvolvimentos de projetos que utilizem as novas tecnologias, para melhorar o ensino aprendizagem dos alunos (Bacich. Neto, \&Trevisani, 2015).

Neste sentido, ao aliar as tecnologias educacionais, torna-se possível criar um ambiente de ensino geograficamente disperso; no entanto, mostra-se necessário que o professor receba treinamento adequado e tenha liberdade de escolher com quais conteúdos sente-se à vontade, para que seja possível atuar como mediador, direcionando seus alunos de forma correta e eficiente para a apropriação do saber (Bertholdo, 2017).

Com esse propósito faz-se necessário mencionar algumas tecnologias educacionais sem a pretensão de esgotar novas possibilidades, mas fomentar a oportunidade de tornar as atividades desenvolvidas no ensino da Enfermagem mais interativas e 
provocativas que levam ao estudo, reflexão e produção de conteúdos com vista ao ensino autônomo do estudante. Desta forma, destaca-se algumas ferramentas usadas no ensino de Enfermagem:

- Jamboard: chamada de lousa digital interativa, permite a edição tanto pelo professor quanto pelos alunos podendo ser editado uma vez compartilhado em contas comuns pelo pacote Gsuíte do Google. É a oportunidade de retirar dúvidas, debater conteúdos e ocasionar novas discussões e pesquisas extraídas desses encontros virtuais para a prática no laboratório de habilidades bem como na discussão prática no campo presencial de ensino clínico;

- $\quad$ Fóruns: através da disponibilidade de conteúdos como hipertextos, artigos, e-books, vídeos assíncronos dentre outros com ênfase no design instrucional é possível realizar debates através de fóruns de discussão com base nos conteúdos planejados. É possível também nos fóruns levar debates sobre casos clínicos que fomentem a construção do conhecimento discente através do planejamento dos cuidados de enfermagem através do processo de enfermagem;

- Blogs Educativos: buscando a interatividade também podem ser elaboradas atividades interativas e colaborativas em grupo onde os discentes constroem um texto autoral e com fontes pesquisadas sobre a aula síncrona em consonância com os conteúdos disponibilizados. Nestes blogs já foram desenvolvidos conteúdos em grupos pelos discentes de enfermagem sobre a importância da vacinação em adultos e idosos, bem como uma campanha educativa sobre a vacinação da COVID-19;

- Site Educativos com visitas virtuais a museus históricos da Enfermagem: oportuno no sentido de levar o discente mesmo que virtualmente aos museus renomados e contextualizar conteúdos abordados na disciplina. Permite ampliar conhecimento, pesquisa e autoria nos conteúdos propostos como atividade;

- Podcasts: é um arquivo digital de áudio transmitido através da internet, cujo conteúdo pode ser variado. Com o intuito de desenvolver a capacidade de oralidade, pesquisa e argumentação reflexiva é uma tecnologia educacional viável de acordo com a proposta da atividade e com os objetivos de aprendizagem que se pretendem alcançar.

- Padlet: é uma outra ferramenta que busca a interatividade com a postagem de conteúdos pelo docente e os alunos. Nesta ferramenta é possível disponibilizar conteúdos ministrados através de um link que pode ser consultado diversas vezes pelos discentes com vistas a produção do conhecimento;

- Metimeter: é uma plataforma online que permite criar apresentações interativas onde os discentes podem responder a vários tipos de perguntas. Essa ferramenta oferece recursos interativos, como nuvem de palavras e questionários, que podem ser compartilhados via internet com seu público-alvo;

- Kahoot: é uma outra plataforma de aprendizado baseada em jogos onde é possível criar questionários sobre qualquer tópico personalizando com vídeos, diagramas e imagens. Os alunos participam em “kahoots” (jogos) registrando os códigos do jogo em seus dispositivos ou aplicativos.

O ensino remoto deve ser inclusivo respeitando as diferenças, propondo medidas que assegure melhoria da qualidade da educação, o investimento com ampla formação dos educadores, a previsão e provisão de recursos materiais e humanos (Camacho, Souza, \& Menezes, 2021). Se torna essencial a elaboração de estratégias de ensino híbrido pelos professores de forma que atenda às necessidades de conhecimento dos discentes e consequentemente de maneira a contribuir para a formação e construção de um profissional de enfermagem capaz de atender com qualidade as demandas da sociedade.

\section{Conclusão}

Com o objetivo descrever algumas tecnologias educacionais no ensino híbrido de Enfermagem com vistas ao desenvolvimento da autonomia discente é preciso entender as suas características que nos ajudam a direcionar as estratégias de ensino, como o respeito do ritmo de aprendizagem de cada aluno, a possibilidade do planejamento do ensino por estações de aprendizagem em grupos e o contínuo planejamento do ensino como algo dinâmico. 
Pensar no ensino híbrido na área da Enfermagem é enfatizar o protagonismo do aluno com autonomia de forma participativa e reflexiva requerendo um ensino interdisciplinar por competências capaz de compreender as demandas do mundo atual. É preciso disposição para inovar, conhecer as ferramentas digitais, saber efetivar as práticas pedagógicas e conhecer a realidade social dos estudantes e professores.

Como limitação é destaque entender maneiras de atender as dificuldades sociais e de vulnerabilidade dos estudantes que possuem problemas no acesso à internet no cotidiano para gerenciar seu aprendizado.

Não obstante, a infraestrutura física institucional deve gerenciar as demandas e necessidades de espaços acadêmico que compreendam as mudanças pedagógicas a partir do ensino híbrido como laboratórios de habilidades e de simulação realística que auxiliam no ensino por grupos. Além de mobiliário flexível, espaço de convivência, estudo e pesquisa, disponibilidade de equipamentos tecnológicos e digitais. Também é oportuno destacar a capacitação docente para viabilidade do ensino híbrido.

\section{Referência}

Andrade, D. P. C. M., \& Monteiro, M. I. (2019). Maria Iolanda. Blended Learning: Practical Approaches in Brazil. Revista Eletrônica Científica Ensino Interdisciplinar, 5(14).

Bacich, L., Neto, A. T., \& Trevisani, F. M. (2015). Ensino Híbrido: personalização e tecnologia na educação. Porto Alegre: Penso Editora Ltda.

Camacho, A. C. L. F., Souza, V. M. F., \& Menezes, H. F. (2021). Ensino remoto sobre processo de enfermagem na pandemia da Covid-19: Relato de Experiência. Research, Society and Development, 10(7): e7210716349.

Castro, E. A. et al. (2015). Ensino híbrido: desafio da contemporaneidade?. Periódico Científico Projeção e Docência, 6(2): 47-58.

Gomes, P. A. L. (2019). Modelo de construção de ambiente de ensino e aprendizagem a distância para estudantes com saúde vulnerável. Ponta Grossa: UTFP.

Júnior, E. R., \& Castilho, N. M. C. (2016). Uma experiência pedagógica em ação: aprofundando o conceito e inovando a prática pedagógica através do ensino híbrido. SIED: EnPED - Simpósio Internacional de Educação a Distância e Encontro de Pesquisadores em Educação a Distância. http://www.siedenped2016.ead.ufscar.br/ojs/index.php/2016/article/view/1295/547.

Machado, N. S., Lupepso, M., \& Jungbluth, A. (2016). Educação híbrida. UFRP: Educação Híbrida. http://cipead.ufpr.br/portal1/materiais/ufpr_hibrida/livro_educacao_hibrida.pdf

Moran, L. B. J. (2017). Metodologias ativas para uma educação inovadora: uma abordagem teórico-prática. Penso Editora Ltda.

Neto, E. B. (2017). O ensino híbrido: processo de ensino mediado por ferramentas tecnológicas. Ponto e Vírgula - PUC SP, (22): 59-72.

Pereira, A. S, Shitsuka, D. M., Parreira, F. J., \& Shitsuka, R. (2018). Metodologia da pesquisa científica. UFSM, NTE.

Pereira, I. S. D., Alvarenga, M. M. S. C., Teixeira, M. C. S., \& Mansur, A. F. U. (2018). Uma proposta metodológica de ensino híbrido envolvendo a plataforma Google Classroom como ambiente virtual de aprendizagem no Ensino Médio. Revista Educação Pública, 1-5.

Rodrigues, E. F. (2016). Tecnologia, inovação e ensino de história: o ensino híbrido e suas possibilidades. Niterói: UFF.

Rolindo, et al. (2019). Modelo híbrido: possibilidade de ensino no século XXI. Brasilian Journal and Development, 5(9): $14262-14279$.

Santos Junior, V. B., \& Monteiro, J.C.S. (2020). Educação E Covid-19: As Tecnologias Digitais Mediando a Aprendizagem em Tempos de Pandemia. Revista Encantar - Educação, Cultura e Sociedade, 2: 01-15.

Santos, A. M. R., \& Hansel, C. G. (2021). Methodology of scientific research in hybrid mode: an experience of integration between health courses. Brazilian Journal of Development, 7(2): 17369-17379.

Santos, C. A. M., Pereira, M. A. C., Barreto, M. A. M., Souza, M. A., \& Cicarelli, P. O. (2019). CEMTRAL: Uma Nova Metodologia Híbrida de Ensino e Aprendizagem. Revista Brasileira de Aprendizagem Aberta e a Distância, 18(1): 1-18.

Schlemmer, E. (2018). Projetos de aprendizagem gamificados: uma metodologia inventiva para a educação na cultura híbrida e multimodal. Momentos: diálogos em educação, 27(1): 42-69.

Silva, N. A., Silva, L. L., Souza, D. S., Viana, J. S., \& Oliveira, J. C. (2021). Tecnologia educacional híbrida- blended learning no olhar do discente de Enfermagem. Research, Society and Development, 10 (4): e25410413899.

Silva, S. S., \& Santos Junior, A. C. P.(2019). Google Sala de Aula como Ambiente Virtual de Aprendizagem no Ensino Superior Híbrido: Uma Revisão da Literatura. EAD em Foco, 9(1): e768.

Weber, E. L., \& Olgin, C. A. (2020). Metodologia de ensino híbrido no ensino superior, uma revisão de literatura, 1-10. 